\title{
Fatigue Test and Lifetime Prediction of Implantable Biocomposite Materials
}

\author{
Jin-Young Choi ${ }^{1}$, Jisoo Kim ${ }^{1}$, Jinyong Shin ${ }^{1}$, Minsu Lee ${ }^{2}$, Tae-Ho Yoon ${ }^{3}$ and Sunmook Lee ${ }^{1^{*}}$ \\ ${ }^{1}$ Korea Conformity Laboratories, 199, Gasandigital 1-ro, Geumchon-gu, Seoul 08503, Republic of Korea \\ 2Osteonic Co, Ltd, Rm 1206, Acetechno Tower III, Digital-ro 29 gil, Guro-gu, Seoul 08381, Republic of Korea \\ ${ }^{3}$ Electronics and Telecommunications Research Institute, 218 Gajeong-ro, Yuseong-gu, Daejeon 34129, Republic of Korea
}

*Corresponding author: Sunmook Lee, Korea Conformity Laboratories, 199, Gasandigital 1-ro, Geumchon-gu, Seoul 08503, Republic of Korea, Tel: +82221022509; Email: sunmooklee@kcl.re.kr

Received date: January 24, 2018; Accepted date: February 06, 2018; Published date: February 12, 2018

Copyright: (c) 2018 Choi JY, et al. This is an open-access article distributed under the terms of the Creative Commons Attribution License, which permits unrestricted use, distribution, and reproduction in any medium, provided the original author and source are credited.

\begin{abstract}
Biocomposite materials consisting of Poly-L-Lactic-Co-Glycolic Acid (PLGA) and Hydroxyapatite (HA) were synthesized and mechanical properties have been observed by carrying out the fatigue test, for which accelerated tests have been conducted such that $20 \%, 30 \%$ and $40 \%$ of the yield strength have been applied in a repeated mode until a crack occurred on the load-applied points of test specimen. Based on the fatigue test results, the lifetime of test specimen $\left(B_{10}\right.$ life) was estimated. It was found that Weibull distribution (shape parameter $=8.79$ ) was the most proper one to describe the failure data obtained from the accelerated fatigue tests. $\mathrm{B}_{10}$ life at $5 \%$ of yield strength was estimated to be 335,764 cycles (Confidence Level=95\%, lower limit) by applying an inverse power model.
\end{abstract}

Keywords: Fatigue test; Lifetime assessment; Implantable; Biocomposite; Reliability

\section{Introduction}

Recently, implantable medical devices consisting of biodegradable polymers such as PLGA or Poly-L-Lactic Acid (PLLA) have been attracting a great deal of attention due to their ease of operation, excellent mechanical properties and, no need of subsequent surgical removal after being implanted in bodies, which is in turn reflected in a significant increase in world-wide market share [1-5]. Inspite of their biodegradable properties, extra benefits such as body constituents cannot be obtained due to their intrinsic nature of chemical formula. There have been challenges to overcome this drawback as well as maximize the usefulness of the implantable medical devices. Among others, bioceramic materials such as $\beta$-Tricalciumphosphate $(\beta$-TCP) or HA have been mixed with biodegradable polymers to form biocomposites. In these types of biocomposite-based medical devices, bone formation can be more facilitated by the absorption of bioceramic components at the implanted sites during the healing period, during which the polymers are completely biodegraded to form $\mathrm{CO}_{2}$ and $\mathrm{H}_{2} \mathrm{O}$. When developed, one of the most important tests that implantable medical devices must satisfy is the biological safety test. However, it is also of great importance to assess the performance durability for manufacturers, especially to assure the quality of the products after sales. One of the most widely accepted and implemented durability test is Q10 test. However, this test only gives the information related to temperature stress conditions. For manufacturers, reliability information [6] related to mechanical properties is also very important ones to consider since they need to assure the performance of their products before they were applied in the human body. Therefore, the lifetime of biocomposite materials in terms of mechanical performance was estimated by conducting accelerated fatigue tests in the present study.

\section{Experimental}

The biocomposite materials used in the present study were made by mixing PLGA and $\beta$-TCP in a 70:30 ratio. Details of the synthetic procedures can be found in the previous study [7]. The yield strength of the biocomposite materials were measured by using Universal Testing Machine (UTM) (TENSILON RTF-1325). The fatigue tests were conducted such that $20 \%, 30 \%$ and $40 \%$ of the yield strength were applied in a repeated mode on a test specimen. The failure of the specimen was determined to be out of the range of $\pm 10 \%$ of initial value (yield strength) as recommended by the manufacturer as described in Table 1.

\begin{tabular}{|c|c|c|}
\hline Sample & $\begin{array}{l}\text { Load Applied (\% of yield } \\
\text { strength) }\end{array}$ & Failure Determination \\
\hline \multirow{3}{*}{$\begin{array}{l}\text { Biocomposite } \\
\text { materials }\end{array}$} & 20 & \multirow{3}{*}{$\begin{array}{l}\text { out of the range of } \pm 10 \% \\
\text { of initial value }\end{array}$} \\
\hline & 30 & \\
\hline & 40 & \\
\hline
\end{tabular}

Table 1: Conditions of accelerated fatigue test on biocomposite materials.

For the estimation of lifetime of biocomposite materials in normal use condition ( $5 \%$ of yield strength), a statistical approach was adopted by using a commercial software program, ALTA ${ }^{\circ}$ (ReliaSoft, USA). Weibull distribution was applied as the lifetime distribution of the biocomposite materials in the present study. Lifetime of biocomposite materials in normal use condition was predicted using the failure time data obtained from the accelerated fatigue tests by adopting an inverse power model. 
Page 2 of 4

\section{Results and Discussion}

The dimension of test specimens prepared for the yield strength was $100 \times 20 \times 1.5 \mathrm{~mm}^{3}$ as shown in Figure 1(a). The yield strengths of the biocomposite materials were measured as shown in Figure 1(b) and the average value was $116.03 \mathrm{~N}$.

(a)

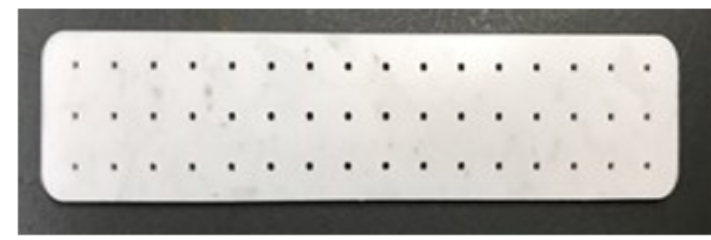

(b)

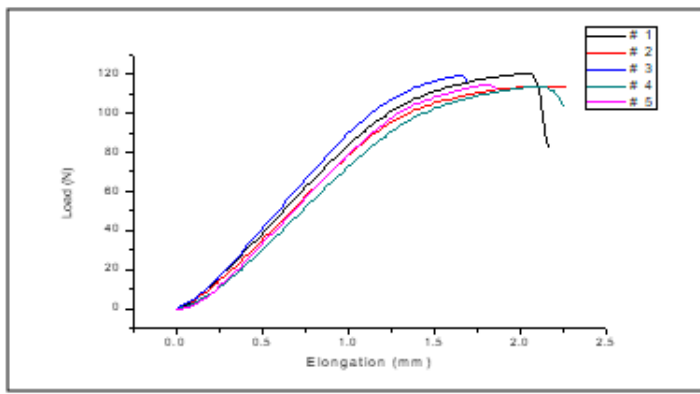

Figure 1: (a) Photo image of test specimen and (b) yield strength of biocomposite materials measured with UTM.

The fatigue test of biocomposite materials was conducted on the middle position of the test specimens in a repeated mode at the rate of $1 / 3 \mathrm{~Hz}$ (load was applied 1 time during the period of 3 seconds) using the fatigue test setup shown in Figure 2(a). The failure time was collected by setting the failure at the point in which the measurement reading was out of the range of $\pm 10 \%$ of initial reading and the failure cycle numbers of the test specimens at each stress level were shown in Table 2.

\begin{tabular}{|l|l|l|}
\hline \multirow{3}{*}{ Stress Level } & Test Specimen & Failure Cycle \\
\hline \multirow{3}{*}{$30 \%$} & $\# 1$ & 13,364 \\
\cline { 2 - 3 } & $\# 2$ & 20,274 \\
\cline { 2 - 3 } & $\# 3$ & 19,163 \\
\hline \multirow{3}{*}{$40 \%$} & $\# 4$ & 5,483 \\
\cline { 2 - 3 } & $\# 5$ & 7,014 \\
\cline { 2 - 3 } & $\# 6$ & 7,603 \\
\hline \multirow{3}{*}{40} & $\# 7$ & 2,529 \\
\cline { 2 - 3 } & $\# 8$ & 3,099 \\
\cline { 2 - 3 } & $\# 9$ & 3,414 \\
\hline
\end{tabular}

Table 2: Failure cycles of biocomposite materials at each stress level.
By using the failure distribution pattern estimated in Figure 2 (b-d), the probability of life (Inverse Power Law-Weibull Distribution) and the relationship between life vs. stress was plotted in Figures 3 and 4 using ALTA: In Figure 3, it was confirmed that the accelerated conditions such as $20 \%, 30 \%$ and $40 \%$ of the yield strength were in the linear range of acceleration. The solid straight line on the right-hand side of Figure 3 indicates the probability of failure at the normal use condition (5\% of the yield strength). With this regard, the common shape and scale parameters were evaluated at the normal use condition (5\% of the yield strength) as shown in Table 3.

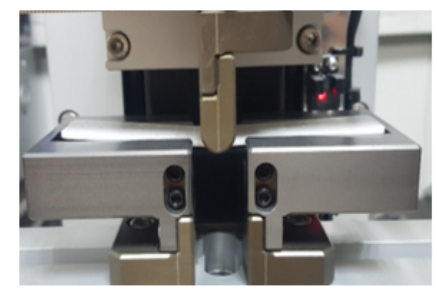

a)

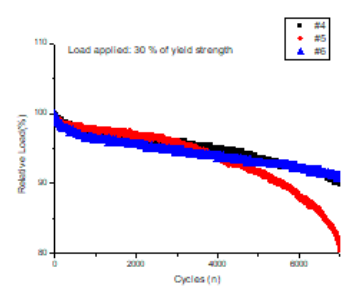

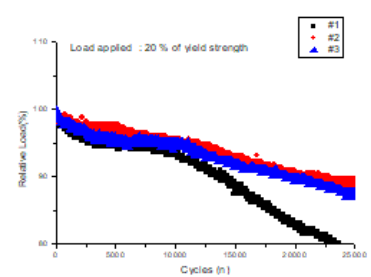

b)

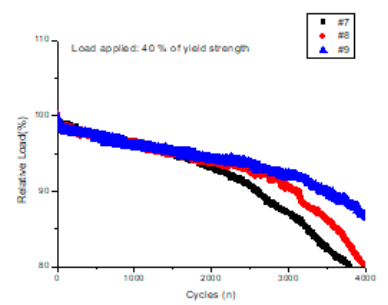

Figure 2: (a) Photo image of fatigue test setup, Photo image of cycle performance under different stress conditions: (b) $20 \%$, (c) $30 \%$ and (d) $40 \%$ of the yield strength.

\begin{tabular}{|c|c|c|c|c|c|}
\hline \multicolumn{2}{|c|}{ Stress level (\%) } & \multirow[t]{2}{*}{$\begin{array}{l}\text { Life } \\
\text { distributio } \\
\mathbf{n}\end{array}$} & \multirow[b]{2}{*}{$\begin{array}{l}\text { Acceleratio } \\
\mathbf{n} \\
\text { model }\end{array}$} & \multirow[b]{2}{*}{$\begin{array}{l}\text { Scale } \\
\text { Parameter } \\
\text { (Eta(cycles)) }\end{array}$} & \multirow[b]{2}{*}{$\begin{array}{l}\text { Shape } \\
\text { Paramet } \\
\text { er (b) }\end{array}$} \\
\hline $\begin{array}{l}\text { Accelerat } \\
\text { ed stress }\end{array}$ & $\begin{array}{l}\text { Normal } \\
\text { use } \\
\text { stress }\end{array}$ & & & & \\
\hline 20 & \multirow[b]{3}{*}{5} & \multirow[b]{3}{*}{ Weibull } & \multirow{3}{*}{$\begin{array}{l}\text { Inverse } \\
\text { Power }\end{array}$} & \multirow[b]{3}{*}{681,575} & \multirow[b]{3}{*}{8.79} \\
\hline 30 & & & & & \\
\hline 40 & & & & & \\
\hline
\end{tabular}

Table 3: Prediction of scale and shape parameters. 
Page 3 of 4

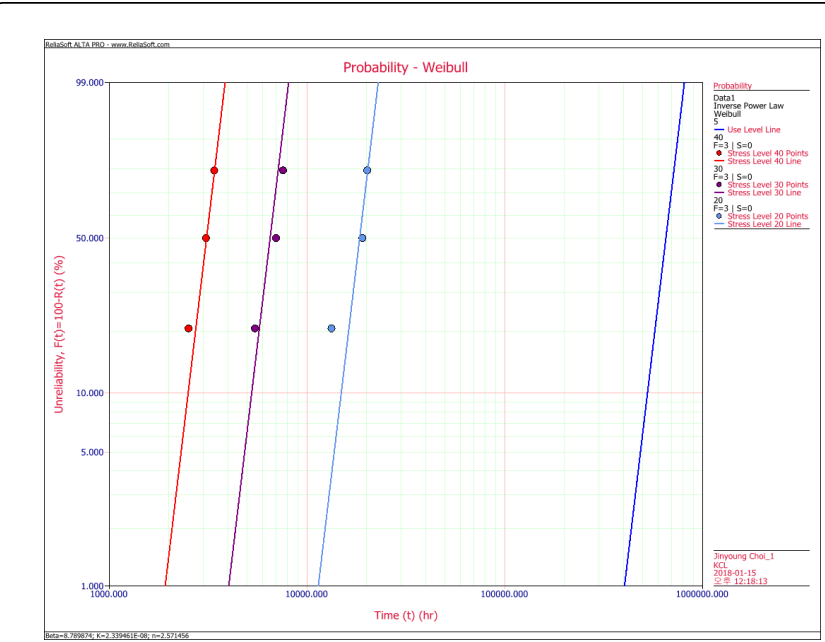

Figure 3: Probability of life (Inverse Power Law and Weibull Distribution).

The applied strength was changed from $20 \%$ to $40 \%$ of the yield strength as shown in Figure 4 and it was found that the overall behavior of failure cycle decreased as the applied strength increased. The reliability and scale parameter lines were shown in straight lines. The upper top line indicated the $90 \%$ unreliability line while the lowest line indicated the $10 \%$ unreliability line, respectively. The middle line indicated the shape parameter line. For example, the reliability began to drop at $20 \%$ approximately after 20,000 cycles, and the reliability began to drop at $30 \%$ approximately after 6,700 cycles, and the reliability began to drop at $40 \%$ approximately after 3,200 cycles. Therefore, the lifetime of the biocomposite materials was getting shorter in the yield strength conditions as the stress levels were getting more severe, which could be verified by the area of the parabola of each stress condition since the lifetime represented by the area was appearing in the shorter time as the stress levels were getting more severe. In addition, the upper limit of lifetime was also appearing in the shorter time as the stress levels were getting more severe.

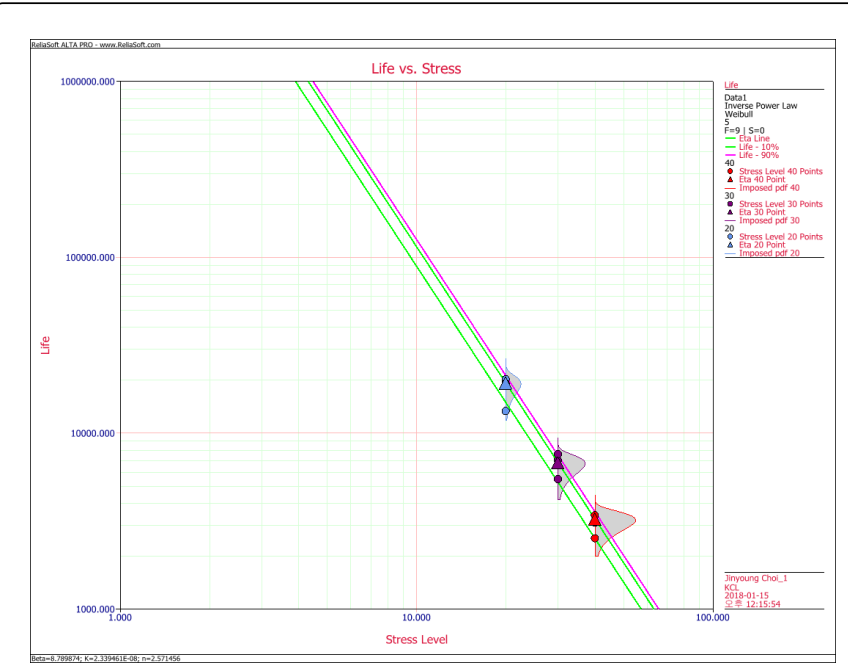

Figure 4: Life-Stress under different stress conditions.
The behavior of probability density function and failure rate with cycle was shown in Figure 5 when the Weibull distribution was applied as the lifetime distribution of the biocomposite materials in the present study. Particularly, Figure 5(a) the failure of the biocomposite materials did not occur at the initial stage of the fatigue test, but it drastically appeared at around 263,000 cycles, and was clouded at around 665,000 cycles. This was also verified by the failure rate in Figure 5(b), since there was an abrupt increase in the failure rate after 900,000 cycles, which is indicative of a typical wear-out failure. It was found that the failure rate showed and IFR (increasing failure rate) mode as shown in Figure 5(b), which indicated that the degradation of the biocomposite materials developed as the stress conditions (yield strength) were getting severe and the failure of the biocomposite materials caused by the degradation drastically were progressed within around 2,000,000 cycles.

The lifetime prediction was made by adopting an inverse power eq. model (1) for life-stress relationship.

$\mathrm{L}=\mathrm{AV}^{-\mathrm{n}}(1)$

- L: Life,

- A, n: constant,

- V: Stress factor.

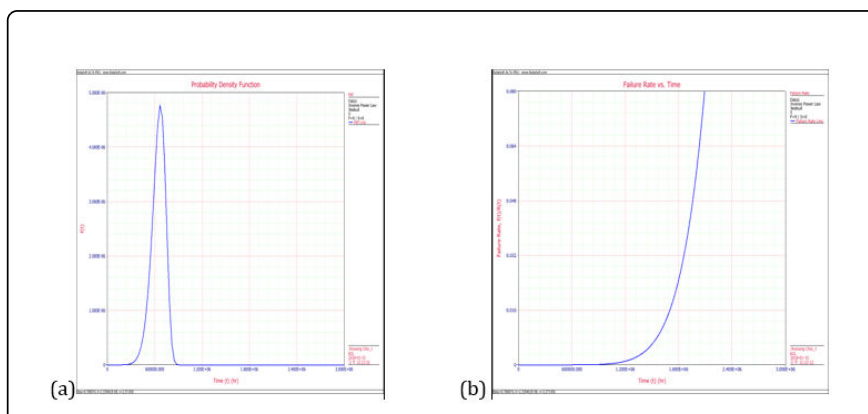

Figure 5: Lifetime behavior of biocomposite materials: (a) Probability density function vs. Cycle and (b) Failure rate vs Cycle.

Using the model equation, the $\mathrm{B}_{10}$ life of biocomposite materials was estimated to be $\mathrm{B}_{10}=335,764$ cycles (lower limit) with confidence level $=95 \%$ as shown in Table 4 . The AF were calculated for each accelerated condition from the Stress-Life relationship by setting $5 \%$ of the yield strength as the actual field condition for use.

\begin{tabular}{|l|l|}
\hline Load applied (\% of yield strength) & $\mathbf{B}_{10}$ Life (CL=95\%, lower limit) \\
\hline $5 \%$ & 335,764 cycles \\
\hline
\end{tabular}

Table 4: Prediction of Lifetime.

$$
\mathrm{AF}=\frac{\mathrm{L}_{\text {use }}}{\mathrm{L}_{\text {accelerated }}}=\frac{\mathrm{AV}_{\mathrm{u}}^{-\mathrm{n}}}{\mathrm{AV}_{\mathrm{a}}^{-\mathrm{n}}}=\left(\frac{\mathrm{V}_{\mathrm{a}}}{\mathrm{V}_{\mathrm{u}}}\right)^{\mathrm{n}}
$$

-Luse: the life at use stress level,

-Laccelerated: the life at the accelerated stress level,

-Vu: use stress level, 
-Va: accelerated stress level,

-A, n: constant.

The effect of stress conditions on the AF were shown in Figure 6. It should be noted that it was not recommended to go over the $40 \%$ of the yield strength since the linearity of the accelerating test condition did not hold at $50 \%$ of the yield strength, for example, shown in the Figure 6, which was due to the different failure modes of $20 \%, 30 \%$ and $40 \%$ of the yield strength from that of $50 \%$ of the yield strength.

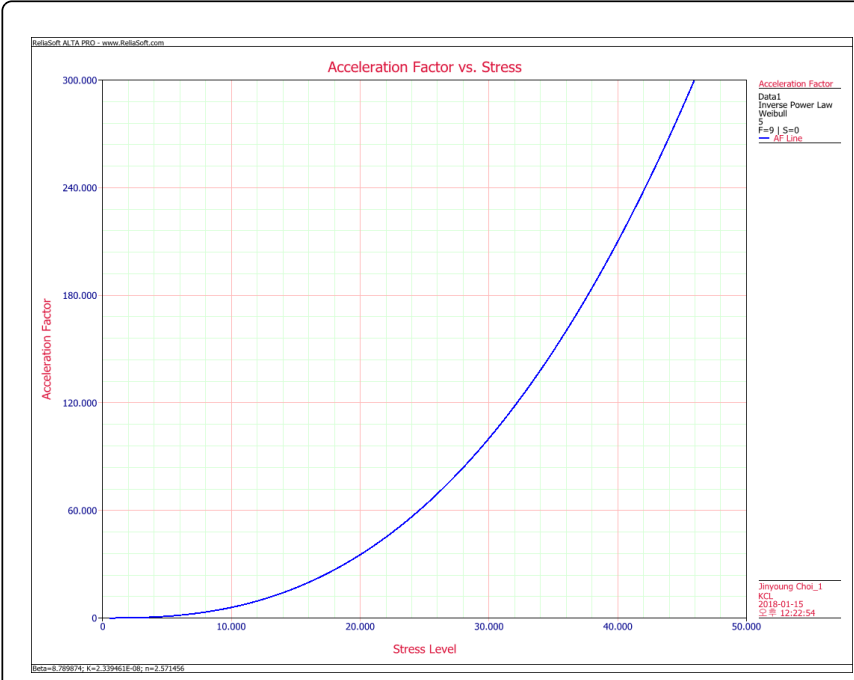

Figure 6: Effect of stress on AF.

\section{Conclusion}

The life of biocomposite materials were estimated through fatigue tests under 3 different accelerated conditions of yield strength. The failure time of the biocomposite materials was determined to be the time when the value at the time of the measurement was out of the range of $\pm 10 \%$ of the initial yield strength. The lifetime prediction was made by adopting an inverse power eq. model for stress-life relationship, and the $\mathrm{B}_{10}$ life (with $\mathrm{CL}=95 \%$ ) was estimated to be 335,764 cycles (lower limit).

\section{Symbol}

$\beta$ : Shape parameter,

\section{A: Constant,}

$\mathrm{B}_{10}$ : a measurement of the time by which ten percent of population of a product will have failed,

\section{CL: Confidence Level,}

\section{AF: Acceleration Factors}

$\mathrm{E}_{\mathrm{ta}}$ : Scale parameter,

L: Lifetime,

$\mathrm{L}_{\text {accelerated }}$ The life at the accelerated stress level,

$\mathrm{L}_{\text {use: }}$ The life at use stress level,

n: Constant,

V: Stress factor,

$\mathrm{V}_{\mathrm{a}}$ : Accelerated stress level,

$\mathrm{V}_{\mathrm{u}}$ : Use stress level.

\section{Acknowledgement}

The authors gratefully acknowledge the financial support from the Ministry of Trade, Industry and Energy and Gangwon Institute for Regional Program Evaluation (Grant Number: R0005237).

\section{References}

1. Anand A, Kumar M, Kodikal G (2010) Role of suture anchors in management of fractures of inferior pole of patella. Indian J Orthop 44: 333-335.

2. Hak DJ, Am J (2007) The use of osteoconductive bone graft substitutes in orthopaedic trauma. Orthop Surg Acad 15: 525-536.

3. Allison DC, Lindberg AW, Samimi B, Mirzayan R, Menendez LR (2011) US Oncology and Hematology 7: 38-49.

4. Milewski MD, Diduch DR, Hart JM, Tompkins M, Ma SY, et al. (2012) Bone replacement of fast-absorbing biocomposite anchors in arthroscopic shoulder labral repairs. Am J Sports Med 40: 1392-1401.

5. Ozbaydar M, Elhassan B, Warner JJ (2007) The use of anchors in shoulder surgery: a shift from metallic to bioabsorbable anchors. Arthorscopy 23: 1124-1126.

6. Choi J, Yang IM, Yoon T, Lee S (2016) Lifetime Assessment of POCT Strips through Accelerated Degradation Test. Pharm Anal Acta 7: 1000475.

7. Hong B, Kwon Y, Zhang S, Lee H, Kim O, et al. (2017) Development of Biocomposite Based Anchor Screw System for Osteoporosis. Solid State Phenomena 266: 252-256. 